\title{
PENENTUAN KLASIFIKASI STATE PADA RANTAI MARKOV DENGAN MENGGUNAKAN NILAI EIGEN DARI MATRIKS PELUANG TRANSISI
}

\author{
Yohanes A.R. Langi ${ }^{1)}$ \\ ${ }^{1)}$ Program Studi Matematika FMIPA Universitas Sam Ratulangi, Manado 95115 \\ e-mail:ylangi@yahoo.com
}

\begin{abstract}
ABSTRAK
Masalah dasar dari pemodelan stokastik dengan proses Markov adalah menentukan deskripsi state yang sesuai, sehingga proses stokastik yang berpadanan akan benar-benar memiliki sifat Markov, yaitu pengetahuan terhadap state saat ini adalah cukup untuk memprediksi perilaku stokastik dari proses di waktu yang akan datang. Penelitian ini dilakukan untuk menentukan klasifikasi state pada rantai Markov yang dibatasi untuk $n=4$. Hasil penelitian ini menunjukkan bahwa untuk, state 4 terdapat satu state absorbing dan tiga state transient. Untuk batasan nilai $1 \geq \lambda_{2} \geq \lambda_{3} \geq$ $0 \geq \lambda_{4}$ terdapat dua state yang transient, dua state yang recurrent, dan membentuk satu kelas ekivalensi, sedangkan untuk batasan nilai $1 \geq \lambda_{2} \geq 0 \geq \lambda_{3} \geq \lambda_{4}$ terdapat dua state yang transient, dua state yang recurrent, dan termasuk state yang recurrent dalam satu kelas ekivalensi.
\end{abstract}

Kat kunci: klasifikasi state, rantai markov, stokastik

\section{DETERMINE CLASSIFICATION OF STATE IN MARKOV CHAIN USING EIGEN VALUE FROM TRANTITION PROBABILITY MATRIX}

\begin{abstract}
Base problem from stochastic modal with Markov process is to determine appropriate state of description, in order that stochastic process corresponding will has truly Markov's characteristic. Recently, it is adequate for knowledge of state to predict process of behavior stochastic in future. The research is intended to determine classification of state in Markov's chain that is restriction to 4. The results indicate that for state,for 4 . A restriction value $1 \geq \lambda_{2} \geq \lambda_{3} \geq 0 \geq \lambda_{4}$ will be formed one state transient, two states recurrent and one class of equivalent, while limited one $1 \geq \lambda_{2} \geq 0 \geq \lambda_{3} \geq \lambda_{4}$ will be formed two states transient, two states recurrent, and including one state recurrent inside one class of equivalent.
\end{abstract}

Keywords: state clasification, marcov chain, stochastic

\section{PENDAHULUAN}

Rantai Markov merupakan sebuah proses stokastik, dimana kejadian pada masa mendatang hanya bergantung pada kejadian hari ini dan tidak bergantung pada keadaan masa lampau. Rantai Markov terdefinisi oleh matriks peluang transisinya. Matriks peluang transisi adalah suatu matriks yang memuat informasi yang mengatur perpindahan sistem dari suatu state ke state lainnya (Langi, 2009). Matriks peluang transisi sering disebut juga matriks stokastik karena peluang transisi $p_{i j}$ adalah tetap dan tidak bergantung pada waktu $t$, dimana $p_{i j}$ adalah peluang transisi satu langkah yang bergerak dari keadaan $i$ ke keadaan $j$. Matriks peluang transisi juga merupakan matriks segi. Melalui matriks peluang transisi maka dapat ditentukan klasifikasi state pada rantai Markov.

Masalah dasar dari pemodelan stokastik dengan proses Markov adalah menentukan deskripsi state yang sesuai, sehingga proses stokastik yang berpadanan akan benar-benar memiliki sifat Markov, yaitu pengetahuan terhadap state saat ini adalah cukup untuk memprediksi perilaku stokastik dari proses di waktu yang akan datang. Sekarang, bagaimana jika penentuan klasifikasi state dikaitkan dengan nilai eigen, apakah hal tersebut bisa dilakukan? Maka di dalam penulisan ini, penulis berusaha membahas pengklasifikasian state-state pada rantai Markov dari sebuah matriks dengan nilai eigen tertentu. Tujuan penelitian adalah untuk menentukan klasifikasi state dalam 
rantai Markov dengan menggunakan nilai eigen dari matriks peluang transisi untuk matriks segi berordo 4 .

\section{TINJAUAN PUSTAKA}

\section{Proses Stokastik}

Proses stokastik didefinisikan sebagai proses menyusun dan mengindeks sekumpulan variabel acak $\left\{X_{t}\right\}$, dengan indeks $t$ berada pada sekumpulan $\mathrm{T}$. Terkadang $\mathrm{T}$ dianggap sebagai sekumpulan bilangan bulat nonnegatif, dan $X_{t}$ merepresentasikan karakteristik terukur yang kita perhatikan pada waktu $t$ (Hillier dan Lieberman, 2008). Himpunan T disebut state atau ruang indeks dari proses stokastik X. State merupakan posisi atau keadaan yang akan ditentukan klasifikasinya.

\section{Proses Markov}

Proses Markov adalah suatu proses stokastik dengan sifat: jika keadaan untuk saat sekarang diketahui, peluang keadaan dari proses disatu langkah ke depan hanya dipengaruhi oleh keadaan proses disaat sekarang. Artinya, keadaan proses diwaktuwaktu lampau tidak mempengaruhi keadaan ke depan.

\section{Rantai Markov}

Rantai Markov mempunyai sifat kunci sebagai berikut: Proses stokastik $X_{t}$ dikatakan mempunyai sifat Markovian jika

$$
\begin{gathered}
P\left\{X_{t+1}=j \mid X_{0}=s_{0}, X_{1}=s_{1}, \ldots, X_{t-1}\right. \\
\left.=s_{t-1}, X_{t}=i\right\}, \\
=P\left\{X_{t+1}=j \mid X_{t}=i\right\}
\end{gathered}
$$

untuk $t=0,1, \ldots$ dan setiap urutan $i, j, s_{0}, s_{1}, \ldots, s_{t-1}$ (Hillier dan Lieberman, 2008). Sifat Markovian ini menyatakan bahwa peluang bersyarat dari "kejadian" mendatang, dengan "kejadian" masa lampau dan state saat ini $X_{t}=i$, adalah independent terhadap kejadian di waktu lalu dan hanya tergantung pada keadaan saat ini (Hillier dan Lieberman, 2008).

Peluang bersyarat $P\left\{X_{t+1}=j \mid X_{t}=\right.$ i) untuk rantai Markov disebut peluang transisi (satu langkah). Jika, untuk setiap $i$ dan $j$,

$P\left\{X_{t-1}=j \mid X_{t=i}\right\}=P\left\{X_{1}=j \mid X_{0}=i\right\}$ untuk $t=1,2, \ldots$

maka peluang transisi (satu langkah) dikatakan stasioner. Oleh karena itu, peluang transisi stasioner menyiratkan bahwa peluang transisi tidak berubah seiring dengan waktu. Keberadaan peluang transisi stasioner (satu langkah) juga menyiratkan bahwa untuk tiap $i, j$, dan $v(v=0,1,2, \ldots)$,

$P\left\{X_{t+v}=j \mid X_{t}=i\right\}=P\left\{X_{v}=j \mid X_{0}=i\right\}$

untuk semua $t=0,1, \ldots$ Peluang bersyarat ini disebut peluang transisi $v$-langkah (Hillier dan Lieberman, 2008).

Untuk menyederhanakan notasi penulisan dengan peluang transisi stasioner, misalkan

$p_{i j}=P\left\{X_{t+1}=j \mid X_{t}=i\right\}$

$p_{i j}^{(v)}=P\left\{X_{t+v}=j \mid X_{t}=i\right\}$

(Hillier dan Lieberman, 2008)

Oleh karena itu, peluang transisi $v$ langkah $p_{i j}^{(v)}$ hanyalah merupakan peluang bersyarat sehingga sistem akan berada pada state $j$ tepat setelah $v$ langkah (satuan waktu), jika sistem tersebut bermula pada state $i$ pada waktu $t$ kapan pun. Oleh karena $p_{i j}^{(v)}$ adalah peluang bersyarat, peluang tersebut harus nonnegatif, dan oleh karena prosesnya harus membuat perubahan ke state lain maka peluang tersebut harus memenuhi sifat

$p_{i j}^{(v)}>0$, untuk semua $i$ dan $j ; \quad v=$ $0,1,2, \ldots$, dan $\sum_{j=0}^{l} p_{i j}^{(v)}=1$ untuk semua $i ; \quad v=0,1,2, \ldots$ dan $j=0,1,2, \ldots, l$ (Hillier dan Lieberman, 2008).

Bentuk matriks (matriks peluang transisi $v$-langkah) untuk menunjukkan semua peluang transisi $v$-langkah adalah:

$$
P_{i j}^{(v)}=\left[\begin{array}{cccc}
p_{00}^{(v)} & p_{01}^{(v)} & \cdots & p_{0 l}^{(v)} \\
p_{10}^{(v)} & p_{11}^{(v)} & \cdots & p_{1 l}^{(v)} \\
\vdots & \vdots & & \vdots \\
p_{i 0}^{(v)} & p_{i 1}^{(v)} & \cdots & p_{i l}^{(v)}
\end{array}\right]
$$

\section{Persamaan Chapman-Kolmogorov}

Persamaan Chapman-Kolmogorov memberikan sebuah metode untuk menghitung peluang transisi $v$-langkah ini:

$P_{i j}^{(v)}=\sum_{k=0}^{l} p_{i k}^{(w)} P_{k j}^{(v-w)}$

untuk semua $i=0,1, \ldots, l ; \quad j=0,1, \ldots$, $l ;$ dan $w=1,2, \ldots, v-1 ; v=w+1, w+2, \ldots$ . (Hillier dan Lieberman, 2008).

Persamaan 6 menunjukkan bahwa dalam perubahan dari state $i$ ke state $j$ sebanyak $v$ langkah, proses ini akan berada dalam beberapa state $k$ setelah tepat $w$ 
(kurang dari $v$ ) state. Oleh karena itu, $p_{i k}^{(w)} P_{k j}^{(v-w)}$ adalah peluang bersyarat dengan titik mulai state $i$, proses menuju ke state $k$ setelah $w$ langkah dan kemudian ke state $j$ setelah $v-w$ langkah. Dengan demikian, penjumlahan peluang bersyarat terhadap semua $k$ yang mungkin akan menghasilkan $p_{i j}^{(v)}$. Untuk $w=1$, maka

$P_{i j}^{(v)}=\sum_{k=0}^{l} p_{i k} p_{k j}^{(w-1)}$

untuk $w=v-1$, maka

$P_{i j}^{(v)}=\sum_{k=0}^{l} p_{i k}^{(v-1)} p_{k j}$

untuk semua state $i$ dan $j$. Rumusan ini memungkinkan peluang transisi $v$-langkah diperoleh dari peluang transisi satu langkah yang diterapkan secara berulang. Untuk $v=2$ rumusan (8) menjadi

$P_{i j}^{(2)}=\sum_{k=0}^{l} p_{i k} p_{k j}$ untuk semua state $i$ dan $j$, dimana $P_{i j}^{(2)}$ merupakan elemen dari matriks $P^{(2)}$. $P^{(2)}$ diperoleh dengan mengalikan matriks peluang transisi satu langkah dengan dirinya sendiri $\left(P^{(2)}=P . P=P^{2}\right)$. Dengan cara yang sama, rumusan di atas untuk $P_{i j}^{(v)}$ mengindikasikan bahwa matriks peluang transisi $v$-langkah adalah:

$P^{(v)}=P P^{(v-1)}=P^{v}$

(Hillier dan Lieberman, 2008).

Oleh karena itu, matriks peluang transisi $v$-langkah $P^{v}$ dapat diperoleh dengan menghitung pangkat ke- $v$ dari matriks transisi satu langkah $\mathrm{P}$.

\section{Klasifikasi State Rantai Markov}

State $j$ dikatakan bisa diakses (accessible) dari state $i$ jika $p_{i j}^{(v)}>0$ untuk beberapa $v \geq 0$ (Hillier dan Lieberman, 2008). Pada umumnya, kondisi yang memadai untuk semua state agar bisa diakses adalah adanya nilai $v$ di mana $p_{i j}^{(v)}>0$ untuk semua $i$ dan $j$.

Jika state $j$ bisa diakses dari state $i$ dan state $i$ bisa diakses dari state $j$ maka state $i$ dan $j$ dikatakan berkomunikasi, dan dinotasikan dengan $i \leftrightarrow j$ (Hillier dan Lieberman, 2008).

Teorema 2.1.

Konsep komunikasi $(\leftrightarrow)$ merupakan suatu relasi ekivalen.
1. State mana pun berkomunikasi dengan dirinya sendiri karena $p_{i i}^{(0)}=$ $P\left\{X_{0}=i \mid X_{0}=i\right\}=1(i \leftrightarrow i)$

2. Jika state $i$ berkomunikasi dengan state $j$ $(i \leftrightarrow j$ ) maka state $j$ berkomunikasi dengan state $i(j \leftrightarrow i)$ karena $i$ dapat diakses dari $j$ dan $j$ dapat diakses dari $i$

3. Jika state $i$ berkomunikasi dengan state $j$ ( $i \leftrightarrow j$ ) dan state $j$ berkomunikasi dengan state $k \quad(j \leftrightarrow k)$ maka state $i$ berkomunikasi dengan state $k(i \leftrightarrow k)$ (Brzeźniak dan Zastawniak, 2002).

Dari teorema di atas, dapat disimpulkan bahwa $\leftrightarrow$ adalah suatu relasi ekivalen. Sebagai hasil dari ketiga sifat komunikasi tersebut, state dapat dibagi menjadi satu kelas atau lebih sehingga state tersebut berkomunikasi satu sama lain dalam kelas yang sama. (sebuah kelas dapat terdiri dari state tunggal) Jika hanya terdapat satu kelas, yaitu semua state berkomunikasi, rantai Markov dikatakan irreducible (tak bisa diperkecil lagi) (Hillier dan Lieberman, 2008).

\section{Definisi 2.1.}

Suatu state $i$ disebut state penyerap (absorbing state) jika $p_{i i}=1$ (Tijms, 2003)

Jika suatu state merupakan state penyerap (absorbing state) maka tidak ada state yang bisa diakses dari state tersebut.

Misalkan $f_{i j}^{(v)}$ menyatakan peluang bahwa, mulai dari state $i$, proses bertransisi untuk pertama kali ke state $j$ terjadi pada waktu $v$. Peluang ini disebut the first-passage time probability. Jadi untuk setiap $v=1,2, \ldots$ $f_{i j}^{v}$

$=P\left\{X_{v}=j, X_{k} \neq j\right.$ untuk semua $\left.1 \leq k \leq v-1 \mid X_{0}=i\right\}$

$, i, j \in I$

$f_{i j}^{0}=0, i, j \in I$ (Tijms, 2003)

Untuk $i, j \in I$

dan

$$
f_{i j}^{1}=p_{i j}
$$

$f_{i j}^{v}=\sum_{k \neq j} p_{i k} f_{k j}^{v-1}$

(Serfozo, 2009).

Selanjutnya untuk setiap $i, j \in I$ didefinisikan

$f_{i j}=\sum_{v=0}^{\infty} f_{i j}^{v}$

(Tijms, 2003)

Jadi, untuk setiap $i, j \in I, f_{i j}$ menyatakan peluang bahwa suatu proses yang dimulai pada state $i$ akan pernah bertransisi ke state $j$. 
Khususnya, untuk setiap state $i, f_{i i}$ menyatakan peluang bahwa suatu proses yang dimulai pada state $i$ akan pernah bertransisi kembali ke state $i$.

\section{Definisi 2.2.}

State dikatakan recurrent (berulang) jika $f_{i i}=1$, sedangkan state dikatakan transient jika $f_{i i}<1$ (Tijms, 2003).

Suatu state dikatakan recurrent bila ketika memasuki state tertentu proses pasti akan kembali ke state itu lagi. Oleh karena itu, state adalah recurrent jika dan hanya jika state tersebut tidak transient. Suatu state dikatakan transient bila ketika memasuki state tertentu proses tidak akan pernah kembali ke state itu lagi. Oleh karena itu, state $i$ dikatakan transient jika dan hanya jika terdapat state $j(j \neq i)$ yang bisa diakses dari state $i$, tetapi tidak sebaliknya, yaitu state $i$ tidak bisa diakses dari state $j$.

\section{METODOLOGI PENELITIAN}

Jika A adalah matriks segi $(n \times n)$ maka kumpulan nilai eigen dari $\mathrm{A}$ dapat dinyatakan sebagai $\sigma=\left(\lambda_{1}, \lambda_{2}, \lambda_{3}, \ldots, \lambda_{n}\right)$, dimana $\lambda_{i} \in R, \forall i=1,2, \ldots, n$. Klasifikasi state dapat ditentukan dengan merubah matriks segi berdasarkan persamaan karakteristi

$\prod_{i=1}^{n}\left(\lambda-\lambda_{i}\right)=|\lambda I-A|=0$

maka dapat ditinjau dalam setiap kasus untuk $n=4$ dengan memisalkan bahwa $\lambda_{1}=1$ dan $\left|\lambda_{i}\right| \leq 1$.

Langkah-langkah yang akan ditempuh dalam penelitian ini adalah:

Untuk $n=4$

1. Memisalkan $\lambda_{2}, \lambda_{3}$ dan $\lambda_{4}$ sebagai nilai eigen

2. Untuk $\lambda_{i} \geq 0, i=2,3,4$

a. Membuat matriks diagonal

b. Merubah matriks diagonal (langkah 3.2. bagian a) menjadi matriks stokastik

c. Menentukan state berdasarkan matriks yang telah diperoleh pada langkah 3.2 bagian $b$

3. Untuk $\lambda_{4} \leq 0 \leq \lambda_{3} \leq \lambda_{2} \leq 1$

a. Mencari nilai $a_{g h}$ melalui determinan dengan menganggap $(\lambda-1)(\lambda-$ $\left.\lambda_{2}\right)\left(\lambda-\lambda_{3}\right)\left(\lambda-\lambda_{4}\right)=\operatorname{det}(\lambda I-$

A)

b. Membuat matriks yang memuat unsurunsur $a_{g h}$ yang telah diperoleh pada langkah 3.3. bagian a

c. Menentukan state berdasarkan matriks yang telah diperoleh pada langkah 3.3. bagian $\mathrm{b}$

4. Untuk $\lambda_{4} \leq \lambda_{3} \leq 0 \leq \lambda_{2} \leq 1$ dan $\lambda_{2} \geq\left|\lambda_{3}\right|$

a. Membuat matriks stokastik

b. Menentukan state berdasarkan matriks yang telah diperoleh pada langkah 3.4. bagian a

5. Untuk $\lambda_{4} \leq \lambda_{3} \leq 0 \leq \lambda_{2} \leq 1$ dan $\lambda_{2}<\left|\lambda_{3}\right|$

a. Membuat matriks stokastik

b. Menentukan state berdasarkan matriks yang telah diperoleh pada langkah 3.5. bagian a

\section{HASIL DAN PEMBAHASAN}

Jika A adalah matriks segi $(n \times n)$ maka kumpulan nilai eigen dari $\mathrm{A}$ dapat dinyatakan sebagai $\sigma=\left(\lambda_{1}, \lambda_{2}, \lambda_{3}, \ldots, \lambda_{n}\right)$, dimana $\lambda_{i} \in R, \forall i=1,2, \ldots, n$. Pada bab ini akan dibahas bagaimana menentukan klasifikasi state dengan merubah matriks segi berdasarkan persamaan karakteristik:

$\prod_{i=1}^{n}\left(\lambda-\lambda_{i}\right)=|\lambda I-A|=0$

maka dapat ditinjau dalam setiap kasus untuk $n=2,3$, dan 4 dengan memisalkan bahwa $\lambda_{1}=1$ dan $\left|\lambda_{i}\right| \leq 1$.

Untuk $n=4$

Misalkan $\sigma=\left(1, \lambda_{2}, \lambda_{3}, \lambda_{4}\right), 1+\lambda_{2}+$ $\lambda_{3}+\lambda_{4} \geq 0$. Ada empat kasus yang akan ditinjau, yaitu:

a. Jika $\lambda_{i} \geq 0, i=2,3,4$

Maka dipilih matriks diagonalnya sebagai berikut:

$$
A=\left[\begin{array}{cccc}
1 & 0 & 0 & 0 \\
0 & \lambda_{2} & 0 & 0 \\
0 & 0 & \lambda_{3} & 0 \\
0 & 0 & 0 & \lambda_{4}
\end{array}\right]
$$

Dari matriks di atas dapat dilihat bahwa matriks tersebut belum merupakan matriks stokatik karena $\lambda_{2}, \lambda_{3}, \lambda_{4}$ belum tentu bernilai satu, sehingga matriks di atas dapat dirubah menjadi matriks stokastik seperti berikut: 
$A=\left[\begin{array}{ccccc}\lambda_{4} & 1-\lambda_{4} & 0 & 0 & \\ 0 & \lambda_{3} & 1-\lambda_{3} & 0 \\ 0 & 0 & \lambda_{2} & 1-\lambda_{2} \\ 0 & 0 & 0 & 1\end{array}\right]$

Dengan diagram transisinya sebagai berikut:

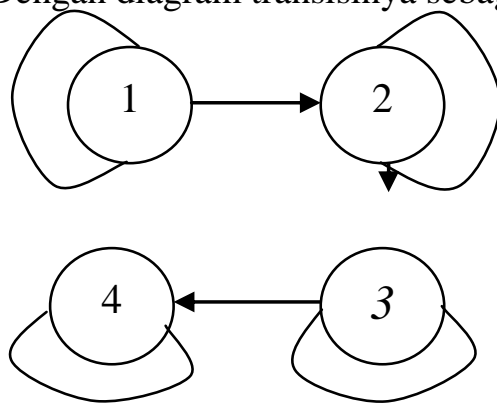

Gambar 1. Diagram Transisi 4 State untuk $\lambda_{i} \geq 0$

Dari diagram transisi di atas dapat dikatakan bahwa state 2 dapat diakses dari state 1 , tetapi state 1 tidak dapat diakses dari state 2. State 3 dapat diakses dari state 2, tetapi state 2 tidak dapat dikases dari state 3 dan state 4 dapat diakses dari state 3 , tetapi state 3 tidak dapat dikases dari state 4 . Dengan demikian dapat dikatakan bahwa state 1, 2, dan 3 merupakan state yang transient, sedangkan state 4 merupakan state yang absorbing karena $p_{44}=1$, sehingga tidak ada state yang dapat diakses dari state 4 .

b. Jika $\lambda_{4} \leq 0 \leq \lambda_{3} \leq \lambda_{2} \leq 1$

Matriks transisinya adalah sebagai berikut:

$$
A=\frac{1}{2}\left[\begin{array}{cccc}
1+\lambda_{4} & 1-\lambda_{4} & 0 & 0 \\
1-\lambda_{4} & 1+\lambda_{4} & 0 & 0 \\
0 & 0 & 2 \lambda_{2} & 0 \\
0 & 0 & 0 & 2 \lambda_{3}
\end{array}\right]
$$

Dapat dilihat bahwa matriks di atas bukan merupakan matriks stokatik karena nilai $\lambda_{2}$ dan $\lambda_{3}$ belum tentu bernilai satu, maka matriks tersebut dapat dirubah menjadi matriks stokastik seperti berikut:

$$
A=\left[\begin{array}{cccc}
\lambda_{3} & 1-\lambda_{3} & 0 & 0 \\
0 & \lambda_{2} & 1-\lambda_{2} & 0 \\
0 & 0 & \frac{1+\lambda_{4}}{2} & \frac{1-\lambda_{4}}{2} \\
0 & 0 & \frac{1-\lambda_{4}}{2} & \frac{1+\lambda_{4}}{2}
\end{array}\right]
$$

Dimana diagram transisinya adalah seperti berikut ini:

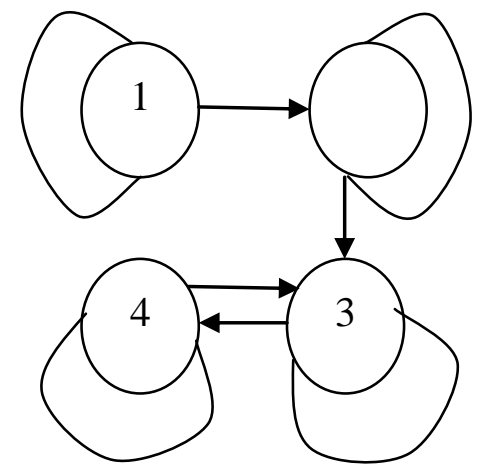

Gambar 2. Diagram Transisi 4 State untuk $\lambda_{4} \leq 0 \leq \lambda_{3} \leq \lambda_{2} \leq 1$

Dari diagram transisi di atas dapat dilihat bahwa state 2 dapat diakses dari state1, tetapi state 1 tidak dapat diakses dari state 2, state 3 dapat dikases dari state 2, tetapi state 2 tidak dapat dikases dari state 3 , sehingga dapat dikatakan bahwa state 1 dan state 2 merupakan state yang transient. Sedangkan state 3 dan state 4 merupakan state yang recurrent karena state 3 dapat diakses dari state 4 dan begitu juga sebaliknya.

c. Jika $\quad \lambda_{4} \leq \lambda_{3} \leq 0 \leq \lambda_{2} \leq$

1 dan $\lambda_{2} \geq\left|\lambda_{3}\right|$

Maka misalkan matriksnya adalah:

$A=\frac{1}{2}\left[\begin{array}{ccrl}1+\lambda_{4} & 1-\lambda_{4} & 0 & 0 \\ 1-\lambda_{4} & 1+\lambda_{4} & 0 & 0 \\ 0 & 0 & \lambda_{2}+\lambda_{3} & \lambda_{2}-\lambda_{3} \\ 0 & 0 & \lambda_{2}-\lambda_{3} & \lambda_{2}+\lambda_{3}\end{array}\right]$

Dari matriks di atas dapat dilihat bahwa matriks tersebut belum merupakan matriks stokastik karena apabila baris ke tiga dan ke empat dijumlahkan akan menghasilkan $\lambda_{2}$, dimana $\lambda_{2}$ belum tentu bernilai satu, sehingga matriks tersebut dapat dirubah menjadi matriks stokastik dalam bentuk:

$$
A=\left[\begin{array}{cccc}
\frac{\lambda_{2}+\lambda_{3}}{2} & \frac{\lambda_{2}-\lambda_{3}}{2} & 1-\lambda_{2} & 0 \\
\frac{\lambda_{2}-\lambda_{3}}{2} & \frac{\lambda_{2}+\lambda_{3}}{2} & 0 & 1-\lambda_{2} \\
0 & 0 & \frac{1+\lambda_{4}}{2} & \frac{1-\lambda_{4}}{2} \\
0 & 0 & \frac{1-\lambda_{4}}{2} & \frac{1+\lambda_{4}}{2}
\end{array}\right]
$$

Dimana diagram transisi dari matriks di atas adalah: 


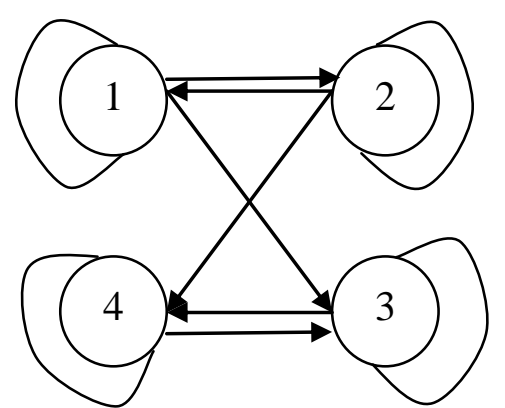

Gambar 3. Diagram Transisi 4 State untuk $\lambda_{4} \leq \lambda_{3} \leq 0 \leq \lambda_{2} \leq 1$ dan $\lambda_{2} \geq\left|\lambda_{3}\right|$

Dari diagram transisi di atas dapat dilihat bahwa state 1 dapat diakses dari state 2 , kemudian state 2 dapat diakses dari state 1 , state 3 dapat diakses dari state 1, tetapi state 1 tidak dapat diakses dari state 3 , sehingga state 1 merupakan state yang transient. Kemudian state 2 dapat diakses dari state 1 dan state 1 dapat diakses dari state 2, selain itu juga, state 4 dapat diakses dari state 2, tetapi state 2 tidak dapat dikases dari state 4 , sehingga state 2 merupakan state yang transient. Selanjutnya state 3 dapat diakses dari state 4 dan sebaliknya state 4 juga dapat diakses dari state 3 sehingga state 3 dan state 4 merupakan state yang recurrent.

d. Jika $\lambda_{4} \leq \lambda_{3} \leq \mathbf{0} \leq \lambda_{2} \leq 1$ dan $\lambda_{2}<\left|\lambda_{3}\right|$

Misalkan:

$\delta_{1}=1+\lambda_{2}+\lambda_{3}+\lambda_{4}$

$\delta_{2}=1+\lambda_{2}+\lambda_{3}-\lambda_{4}$

$\delta_{3}=-\left(\lambda_{2}+\lambda_{3}\right) ; \delta_{4}=1+\lambda_{3}$

$\delta_{5}=-2 \lambda_{3}$

Maka matriksnya adalah:

$$
A=\frac{1}{2}\left[\begin{array}{cccc}
\delta_{1} & \delta_{2} & \delta_{3} & \delta_{3} \\
\delta_{2} & \delta_{1} & \delta_{3} & \delta_{3} \\
\delta_{4} & \delta_{4} & 0 & \delta_{5} \\
\delta_{4} & \delta_{4} & \delta_{5} & 0
\end{array}\right]
$$

Diagram transisi dari matriks tersebut adalah:

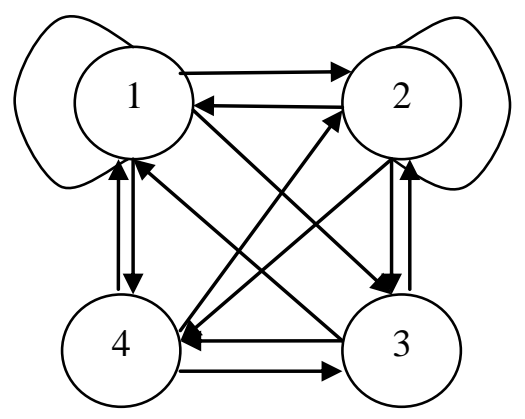

Gambar 4. Diagram Transisi 4 State untuk $\lambda_{4} \leq \lambda_{3} \leq 0 \leq \lambda_{2} \leq 1$ dan $\lambda_{2}<\left|\lambda_{3}\right|$

Berdasarkan diagram transisi di atas, maka dapat dikatakan bahwa state-statenya termasuk state yang recurrent dan merupakan satu kelas ekivalensi.

\section{KESIMPULAN}

Untuk state 4, dimana nilai eigennya 1 , $\lambda_{2}, \lambda_{3}$ dan $\lambda_{4}$, dengan $\lambda_{i} \geq 0, i=2,3,4$ akan terdapat 1 state absorbing dan 3 state transient, sedangkan untuk $\lambda_{4} \leq 0 \leq \lambda_{3} \leq$ $\lambda_{2} \leq 1$ akan terdapat 2 state yang transient dan 2 state yang recurrent juga akan terdapat 1 kelas ekivalensi. Jika $\lambda_{4} \leq \lambda_{3} \leq 0 \leq$ $\lambda_{2} \leq 1$ akan terdapat 2 state yang transient dan 2 state yang recurrent dan juga statenya termasuk state yang recurrent dalam 1 kelas ekivalensi

\section{DAFTAR PUSTAKA}

Anton, H. 1991. Aljabar Linier Elementer Edisi Ketiga. Terjemahan Pantur Silaban dan I. Nyoman Susila. Penerbit Erlangga, Jakarta

Bhat, Narayan. 2008. An Introduction to Queueing Theory. Birkhäuser, Boston.

Brzeźniak and Zastawniak. 2002. Basic Stochastic Processes. Springer, London.

DeGroot, Morris. 1986. Probability and Statistics Second Edition. AddisonWesley Publishing Company, London.

Grinstead, Charles and Snell, Laurie. [tahun terbit tidak diketahui]. Introduction to Probability. [penerbit tidak diketahui], [tempat tidak diketahui]. 
Hadley, G. 1992. Aljabar Linear Edisi Revisi. Penerbit Erlangga, Jakarta.

Hillier, F. S., and Lieberman, G. J. 2008. Introduction to Operation Research. 8th EditionJilid 2. Penerbit Andi, Yogyakarta.

Langi, Yohanes. 2009. Penentuan Klasifikasi State pada Rantai Markov. Jurnal Ilmiah Sains. 9(1):63-67.

Serfozo, Richard. 2009. Basic of Applied Stochastic Processes. Springer, Berlin.

Tijms, H. 2003. A First Course in Stochastic Models. John Willey \& Sons, England. 